\title{
Optimal Shift Scheduling at Ibu Pejabat Polis Daerah (IPD) Kuala Muda using Goal Programming
}

\author{
Sharifah Fhahriyah Syed Abas ${ }^{1 *}$, Jasmani Bidin², Nurul Aatikah Abdul ${ }^{3}$ \\ ${ }^{1,2,3}$ Faculty of Computer and Mathematical Sciences, \\ Universiti Teknologi MARA Perlis Branch, Arau Campus, 02600 Arau, Perlis, Malaysia \\ Corresponding author: *sfhahriyah@uitm.edu.my \\ Received Date: 18 July 2021 \\ Accepted Date: 27 August 2021 \\ Published Date: 13 September 2021
}

\section{HIGHLIGHTS}

- Goal Programming is able to model a set multiple objectives with a number of constraints such as a problem involving unsystematic and complex shift working scheduling.

- The new optimal shift schedule is generated easier and faster with the application of mathematical programming software such as LINGO.

- The new generated schedule is equally balance work schedule and working hours.

- If all constraints and employees' preferences are considered in the model, this new schedule will indirectly boost the workers' motivation to perform better in their work.

\begin{abstract}
Many workplaces encounter complex problems in preparing an optimal work scheduling to meet the 24 hours work demand especially in shift working hours. The schedule needs to consider many constraints and multi objectives at the same time. A mathematical model such as Goal programming is able to cater this kind of problems. Thus, this study was designed to provide a systematic and optimal schedule for police officers at Criminal Unit, IPD Kuala Muda, Kedah. This study is aimed to formulate the best model for the shift rotating schedule of the police officers and to find the best way to optimize the police scheduling related to the limitations, requirements of the police station and the preferences of the police. Lingo software is used to run the model. However, only one out of three goals set for the study was achieved. The new schedule obtained shows that all police officers have the same number of working days, which is 21 days in the 28day planning period. The new schedule produced is better than the previous manual schedule since it takes less time to prepare it without neglecting the constraints involved. To improve efficiency and flexibility on the generated schedules, it is recommended to use other methods such as hybrid swarm-based optimization and many new limitations and preferences should be also considered in the analysis.
\end{abstract}

Keywords: shifts, constraints, police officer's schedule, goal programming, Lingo software

\section{INTRODUCTION}

Shift work is a normal practice for many working sectors which are being operated for 10 to 24 hours per day. Musliu et al. (2018) said rotating workforce scheduling is a worker scheduling problem that havebeen arise in many areas of life. The professions such as police officers, nurses, fire fighters and factory workers 
have to follow their shift or rotating schedule. However, a large number of workers are stressed at their workplace due to many reasons such as longer working period, less time rest, more often working at night shift or weekend, unfair and unbalance schedule. The employers have a problem in the allocation of workers to meet the shifting hours and day to day demand and consume longer period in preparing the shift schedule periodically. These scheduling problems might cause uneasy to the employee. Hence, the performance and the productivity of the company would drop down. Thus, there is a need to solve or minimize the problems of scheduling by properly organized an appropriate scheduling in allocating the resources including manpower without neglecting the voice of the employee and the vision of the company. However, sometimes there exists conflicts between the employees' interest and the company visions and missions. The effective multi-objective programming model, such as goal programming (GP) is suitable in analyzing and solving problem of scheduling by considering limited resources and a number of objective constraints.

GP model, a multi-objective programming (MOP) method, is the development of Linear Programming, a mathematical tool for managing multiple and different objectives. The model is suitable for any strategic decision making because it combines multiple objectives although there exists competing and opposing objectives (Colapinto, et al, 2020). Besides, GP model is also used in making decision making especially involve in optimizing profit and budgetary allocation (Dan et al, 2013). Pre-emptive priority waited goal programming is helpful in finding solutions to small-scale industry issues that include customer satisfaction. This method may increase or decrease the quantity of the product, and the total profit of the company will also be increased (Kumar, 2019). The main idea of GP is to determine the target levels for objective functions and to minimize any (positive or negative) deviations from those levels. The GP model is based on mathematical programming, which is usually solved using software of mathematical programming such as LINGO, MATLAB and AMPL in order to provide effective solutions.

GP model has been applied in many scheduling problems. For example, a study conducted by Todovic et al. (2015) formulated a mathematical model, GP to address the problem of police scheduling in Bosnia and Herzegovina. This study has found that the monthly scheduling of the police officers is actually difficult and complex. Using GP model has reduced the time for police officers to prepare a better organized schedule than before. Besides that the nurse scheduling problem in the outpatient department of the OldTafo Government Hospital was also solved by GP model (Agyei, Obeng-Denteh, and Andaam ,2015). The hospital normally used manual schedules prepared by the head nurse, which are difficult and timeconsuming. The resulting schedule does not usually ensure that the distribution of work among nurses is fair, given 3 the presence of many constraints. The problem was formulated as a 0-1 goal programming model with the aim of the study of consistently equalizing the workload and fulfilling the preferences of nurses without neglecting the hospital rules. The model has considered the workload of the shift allocation, the fairness of the number of consecutive night shifts, and the satisfaction of the nurses' preferences. Finally, the nurse schedules ware improved as compared to the manual schedules. Besides that, GP models were also applied in optimizing the schedule of staffs at electronic industrial (Mahmud et al.,2018) and in teaching load allocation of academic staffs (Mat Salleh, et al.,2019). Hence, the findings have shown that the schedule and allocation is better than before.

In this study, GP model was applied in optimizing the police officer schedule. The shift of police officers must be well organized to prevent the low quality of police officers in their work. Studies has revealed that officers with higher levels of stress are less satisfied with their jobs (Hassell et al., 2010) and a good quality of work life causes an effectiveness in work performance and becomes the most important elements in an organization (Punluekdej, 2020). The police station is one of the facilities that has a significant role to play in the representation of the civil government authority. Moreover, police stations are also known as busy locations. In the police station, there are different ranks and duties between police officers. They are known to be one of the most important people in the country who are needed 24 hours a day. Peterson et al. (2019) stated that major cause of occupational stress for police officer is shift work, which involves rotating, fixed, 
and irregular shift schedules. The police are responsible for maintaining public order and security and for enforcing the law in order to protect the country. Their schedules usually depend on the type of problems that have occurred on that day and time. Therefore, the optimal schedules for assigning police officers to work on shifts need to be well prepared and organized.

\section{METHODOLOGY}

The data from the 24-hour police station criminal unit, IPD Kula Muda was collected through an interview one of the police officers, who is responsible for setting up the schedule for other police officers. The questions in the interview session were on the total number of police officers working in the unit, the duration of their shifts, the number of working days per week and month, the number of shifts of police officers involved and other requirements related to their work. The information about police shift schedule is represented in Table 1 below.

Table 1: Time in and time out of shift

\begin{tabular}{|c|l|c|}
\hline Shifts & Time in & Time out \\
\hline Morning & $7: 00 \mathrm{am}$ & $1: 00 \mathrm{pm}$ \\
\hline Evening & $1: 00 \mathrm{pm}$ & $7: 00 \mathrm{pm}$ \\
\hline Night & $7: 00 \mathrm{pm}$ & $1: 00 \mathrm{am}$ \\
\hline Midnight & $1: 00 \mathrm{am}$ & $7: 00 \mathrm{am}$ \\
\hline
\end{tabular}

The police scheduling problem has hard constraints and soft constraints. Hard constraints are the regulation of the police station, while soft constraints are the preferences of the police officers. The development of the police scheduling model in this study is based on the rules and preferencesof the police officers in order to achieve the goals of the study. The development of decision- making problems are described as follows:

- The unit operates four shifts with 6 hours of morning shift (7:00 a.m.-1:00 p.m.), 6 hours of evening shift (1:00 p.m.-7:00 p.m.), 6 hours of night shift (7:00 p.m.-1:00 a.m.) and 6 hours of midnight shift (1:00 a.m.-7:00 a.m.).

- $\quad$ Minimum staff level requirements have to be met.

- $\quad$ Every police officer has to work for 6 hours on every shift.

- $\quad$ Every police officer must work for 21 days on a 4-week schedule.

- $\quad$ No police officer can work for more than 5 consecutive working days.

- $\quad$ The police who work on the night shift are not allowed to work on the next morning shift.

- The request for a day off should be taken into consideration.

- The number of police officers required for the morning shift is at least 4 staffs, the eveningshift is at least 4 staffs, the night shift is at least 3 staffs and the midnight shift is at least 3 staffs.

- $\quad$ Each police officer is not required to work more than 6 hours a day.

\section{Notation}

The following notations are used to in the model: 
$n=$ number of days in schedule $(n=28)$.

$m=$ number of policemen available $(m=28)$.

$i=$ index for days, $i=1,2,3, \ldots, n$.

$k=$ index for each policeman, $k=1,2,3, \ldots, m$.

$Q_{i}=$ police officers needed for morning shift for a day.

$R_{i}=$ police officers needed for evening shift for a day.

$S_{i}=$ police officers for night shift for a day.

$T_{i}=$ police officers for midnight shift for a day.

\section{Decision Variables}

The decision variables are described as follows:

$$
\begin{aligned}
M_{i, k} & =\left\{\begin{array}{l}
1, \text { if police } k \text { is assigned morning shift for day } i \\
0, \text { otherwise }
\end{array}\right. \\
E_{i, k} & =\left\{\begin{array}{l}
1, \text { if police } k \text { is assigned } \text { evening shift for day } i \\
0, \text { otherwise }
\end{array}\right. \\
N_{i, k} & =\left\{\begin{array}{l}
1, \text { if police } k \text { is assigned night shift for day } i \\
0, \text { otherwise }
\end{array}\right. \\
X_{i, k} & =\left\{\begin{array}{l}
1, \text { if police } k \text { is assigned midnight shift for day } i \\
0, \text { otherwise }
\end{array}\right. \\
C_{i, k} & =\left\{\begin{array}{l}
1, \text { if police } k \text { is assigned day -off for day } i \\
0, \text { otherwise }
\end{array}\right.
\end{aligned}
$$

where $M=$ morning shift. $E=$ evening shift, $N$ - night shift, $X=$ midnight shift, and $C=$ day - off

\section{Hard Constraints}

Hard constraint is the regulation of a police station. The formulations of the hard constraints is described as follows:

Set 1: The minimum number of police officers required for each shift must be met.

$$
\begin{gathered}
\sum_{k=1}^{m} M_{i, k} \geq Q_{i}, i=1,2, \ldots n \\
\sum_{k=1}^{m} E_{i, k} \geq R_{i}, i=1,2, . . n
\end{gathered}
$$




$$
\begin{aligned}
& \sum_{k=1}^{m} N_{i, k} \geq S_{i}, i=1,2, \ldots n \\
& \sum_{k=1}^{m} X_{i, k} \geq T_{i}, i=1,2, \ldots n
\end{aligned}
$$

Set 2: Each police officer works only one shift per day.

$$
\sum_{k=1}^{m} M_{i, k}+E_{i, k}+N_{i, k}+X_{i, k}+C_{i, k}=1, \quad i=1,2, \ldots, n \text { and } k=1,2, \ldots, m
$$

Set 3: Each police officer must work from 20 to 22 days on a 4 week schedule.

$$
\begin{aligned}
& \sum_{i=1}^{n m}\left(M_{i, k}+E_{i, k}+N_{i, k}+X_{i, k}\right) \geq 20, k=1,2, \ldots, m \\
& \sum_{i=1}^{n m}\left(M_{i, k}+E_{i, k}+N_{i, k}+X_{i, k}\right) \leq 22, k=1,2, \ldots, m
\end{aligned}
$$

Set 4: Each police officer who has to work 3 consecutive midnight shifts must have 2 days off the next day.

$$
\begin{aligned}
& X_{1, k}+X_{2, k}+X_{3, k}+C_{4, k}+C_{5, k}=5, \quad k=1,2, \ldots, m \\
& X_{4, k}+X_{5, k}+X_{6, k}+C_{7, k}+C_{8, k}=5, \quad k=1,2, \ldots, m \\
& X_{7, k}+X_{8, k}+X_{9, k}+C_{10, k}+C_{11, k}=5, \quad k=1,2, \ldots, m \\
& X_{10, k}+X_{11, k}+X_{12, k}+C_{13, k}+C_{14, k}=5, \quad k=1,2, \ldots, m \\
& X_{13, k}+X_{14, k}+X_{15, k}+C_{16, k}+C_{17, k}=5, \quad k=1,2, \ldots, m \\
& X_{16, k}+X_{17, k}+X_{18, k}+C_{19, k}+C_{20, k}=5, \quad k=1,2, \ldots, m \\
& X_{19, k}+X_{20, k}+X_{21, k}+C_{22, k}+C_{23, k}=5, \quad k=1,2, \ldots m \\
& X_{22, k}+X_{23, k}+X_{24, k}+C_{25, k}+C_{26, k}=5, \quad k=1,2, \ldots, m
\end{aligned}
$$




$$
X_{25, k}+X_{26, k}+X_{27, k}+C_{28, k}=4, \quad k=1,2, \ldots, m .
$$

Set 5: Each police officer must work not more than 7 consecutive days.

$$
C_{i, k}+C_{i+1, k}+C_{i+2, k}+C_{i+3, k}+C_{i+4, k}+C_{i+5, k}+C_{i+6, k} \geq 1, i=1,2, ., n \text { and } k=1,2, . m
$$

\section{Soft Constraints}

Soft constraint is the preferences of police officers. The formulation of soft constraints are described as follows:

Set 1: It avoids working in a night shift followed by a morning shift on the next day.

$$
\begin{aligned}
& N_{i, k}+M_{i+1, k} \leq 1, \quad i=1,2, \ldots, n-1 \text { and } k=1,2, \ldots, m \\
& N_{n, k}+M_{1, k+1} \leq 1, \quad k=1,2, \ldots, m-1 \\
& N_{n, m}+M_{1,1} \leq 1
\end{aligned}
$$

Set 2: It avoids working in a night shift followed by a midnight shift on the next day.

$$
\begin{aligned}
& N_{i, k}+X_{i+1, k} \leq 1, \quad i=1,2, \ldots, n-1 \text { and } k=1,2, \ldots, m \\
& N_{n, k}+X_{1, k+1} \leq 1, \quad k=1,2, \ldots, m-1 \\
& N_{n, m}+X_{1,1} \leq 1
\end{aligned}
$$

Set 3: Based on the preferences of the police officer, every police officer should work only for 21 days.

$$
\sum_{i i=1}^{n}\left(M_{i, k}+E_{i, k}+N_{i, k}+X_{i, k}\right)=21, \quad \mathrm{k}=1,2, \ldots, \mathrm{m}
$$

\section{Goals}

The goal is to combine hard constraints and soft constraints in order to achieve the objective of the study. The goals are set out as follows:

Goal 1: It is to ensure that all police officers only have 21 working days on a 4 week schedule. 
$\eta 1_{k}$ (ST1) is the amount of negative deviation respectively to $\rho 1_{k}$ (PO1) which is the amount of positive deviation from goal 1 for police $\mathrm{k}$. Both the negative and the positive deviations will be penalized.

$$
\sum_{i i=1}^{n}\left(M_{i, k}+E_{i, k}+N_{i, k}+X_{i, k}\right)+\eta 1_{k}-\rho 1_{k}=21, \quad k=1,2, \ldots, m
$$

Goal 2 : It prevents a police officer from being assigned a midnight shift the next day after he night shift or evening shift, $\eta 2_{k}(S T 2)$ is the amount of negative deviation to $\rho 2_{k}(P O 2)$ which is the amount of positive deviation from goal 2 for police $\mathrm{k}$ respectively. Only positive deviations are penalized.

$$
\begin{aligned}
& N_{i, k}+X_{i+1, k}+\eta 2_{k}-\rho 2_{k} \leq 1, i=1,2, \ldots, n-1 \text { and } k=1,2, \ldots, m \\
& N_{n, k}+X_{1, k+1}+\eta 2_{n, k}-\rho 2_{n, k} \leq 1, k=1,2, \ldots, m-1 \\
& N_{n, m}+X_{1, l}+\eta 2_{n . m,}-\rho 2_{n, m} \leq 1
\end{aligned}
$$

Goal 3: It prevents a police officer from having a morning shift the next day after working on a night shift that day. $\eta 3_{k}(S T 3)$ is the amount of negative deviation in respect $\rho 3_{k}(P O 3)$ of which is the amount of positive deviation from Goal 3 for police k. Only positive deviations will be penalized.

$$
\begin{aligned}
& N_{i, k}+M_{i+1, k}+\eta 3_{k}-\rho 3_{k} \leq 1, i=1,2, \ldots, \mathrm{n}-1 \text { and } k=1,2, \ldots, m \\
& N_{n, k}+M_{1, k+1}+\eta 3_{n, k}-\rho 3_{n, k} \leq 1, k=1,2, \ldots, m-1 \\
& N_{n, m}+M_{1, l}+\eta 3_{n \cdot m,}-\rho 3_{n, m} \leq 1
\end{aligned}
$$

\section{Assigning Importance Weights}

The importance of the weights given to the goals shows the relative importance of the goals to be compared with the others. The penalty for these goals shows their importance of the goals to be compared with the other. The penalty for these goals shows their importance in this model. Goal 1, which ensures that all police officers have only 21 working days on a 4-week schedule, is considered to be the most goal followed by Goal 2 and Goal 3.

Thus, the pre-emptive goal programming for this model is defined as follows :

$$
\text { Minimize : }\left(\sum_{k=1}^{m}\left(\eta 1_{k}+\rho 1_{k}\right), \sum_{i=1}^{n} \sum_{k=1}^{m} \rho 2_{i, k}, \sum_{i=1}^{n} \sum_{k=1}^{m} \rho 3_{i, k}\right)
$$

Subject to :

Equations (1)-(17);

Equations (18)-(32)

Copyright@ 2021 UiTM Press. This is an open access article under the CC BY-NC-SA (https://creativecommons.org/licenses/by-nc-sa/4.0//) 
where $\mathrm{Q}=0$ or $1, \mathrm{R}=0$ or $1, \mathrm{~S}=0$ or $1, \mathrm{~T}=0$ or $1, \mathrm{C}=0$ or 1 , and $\eta 1, \rho 1, \eta 2, \rho 2, \eta 3, \rho 3 \geq 0$.

\section{FINDINGS AND DISCUSSIONS}

The goal programming model was implemented in preparing the shift schedule at IPD Kuala Muda criminal unit of 28 police officers where at least 4 police officers required for the morning shift, at least 4 police officers on the evening shift, at least 3 police officers on the night shift, and at least 3 police officers on the midnight shift. The model is optimized for one goal at a time. This model was therefore solved using Lingo software. The status of the Lingo solver showed the output of the data, the details of the model developed and the achievement of the model. It has shown that an optimum solution has been found. Since the output of lingo showed the objective value is zero, this indicates that the model has achieved the optimum solution. Thus, the model shown here is an appropriate model for police officer schedules.

The results of the goal programming model obtained using Lingo software is summarized in Table2, Table 3 and Table 4.

Table 2: Schedule developed using 0-1 goal programming model

\begin{tabular}{|c|c|c|c|c|c|c|c|c|c|c|c|c|c|c|c|c|c|c|c|c|c|c|c|c|c|c|c|c|}
\hline \multicolumn{29}{|c|}{$\begin{array}{l}\text { POLICE } \\
\text { OFFICER }\end{array}$} \\
\hline DAY & 1 & 2 & 3 & 4 & 5 & 6 & 7 & 8 & 9 & 10 & 11 & 12 & 13 & 14 & 15 & 16 & 17 & 18 & 19 & 20 & 21 & 22 & 23 & 24 & 25 & 26 & 27 & 28 \\
\hline 1 & $x$ & $x$ & $x$ & $x$ & $M$ & $E$ & $M$ & $\mathrm{~N}$ & $M$ & $\mathrm{~N}$ & $X$ & $x$ & $x$ & $E$ & $M$ & $x$ & $E$ & $M$ & $x$ & $E$ & $x$ & $E$ & $E$ & $\mathrm{M}$ & $x$ & $M$ & $\mathrm{~N}$ & $x$ \\
\hline 2 & $x$ & $x$ & $x$ & $x$ & & $\mathrm{~N}$ & & $E$ & $M$ & $E$ & & & $M$ & & & & $\mathrm{~N}$ & $E$ & $\mathrm{~N}$ & & $E$ & $E$ & & $E$ & $M$ & $E$ & $E$ & $M$ \\
\hline 3 & $x$ & $x$ & $x$ & $x$ & & & & $M$ & $E$ & $M$ & $M$ & $E$ & $E$ & $E$ & $E$ & & $E$ & $E$ & $\mathrm{~N}$ & $X$ & $\mathrm{~N}$ & $E$ & $M$ & $E$ & $\mathrm{~N}$ & $E$ & $E$ & $E$ \\
\hline 4 & & & & & $X$ & $x$ & $X$ & & $\mathrm{~N}$ & $\mathrm{~N}$ & & & & $M$ & & $E$ & $E$ & & & & $\mathrm{~N}$ & & $E$ & $M$ & $E$ & & $M$ & $M$ \\
\hline 5 & & & & & $X$ & $x$ & $X$ & & $\mathrm{~N}$ & $E$ & $M$ & & & & & & & $\mathrm{~N}$ & $\mathrm{M}$ & $\mathrm{N}$ & $E$ & $E$ & & & $M$ & $E$ & $M$ & \\
\hline 6 & M & $E$ & $E$ & & $x$ & $x$ & $x$ & & & & & & & & & $\mathrm{~N}$ & $\mathrm{~N}$ & $E$ & $M$ & $E$ & & & $M$ & $\mathrm{~N}$ & $M$ & & & \\
\hline 7 & $E$ & $E$ & $E$ & M & & & & $X$ & $X$ & $x$ & & M & & & $\mathrm{N}$ & $E$ & $\mathrm{~N}$ & $\mathrm{~N}$ & & & M & & $M$ & & & & & \\
\hline 8 & $\mathrm{~N}$ & $M$ & $E$ & $E$ & & & & $x$ & $x$ & $X$ & & $\mathrm{~N}$ & $E$ & $\mathrm{E}$ & $\mathrm{N}$ & $M$ & & & & & & $\mathrm{M}$ & & $\mathrm{M}$ & & & & \\
\hline 9 & $\mathrm{~N}$ & & $M$ & $E$ & $E$ & & $M$ & $x$ & $x$ & $x$ & $M$ & & & $E$ & & & & & $\mathrm{~N}$ & & M & $E$ & & & & & & $\mathrm{~N}$ \\
\hline 10 & & & & $E$ & $E$ & $\mathrm{M}$ & $E$ & & & & $X$ & $X$ & $X$ & $\mathrm{~N}$ & $\mathrm{~N}$ & $E$ & & & & $\mathrm{~N}$ & & & M & $\mathrm{M}$ & & & $\mathrm{M}$ & \\
\hline 11 & & & & & $M$ & M & $M$ & & & & $X$ & $X$ & $x$ & $\mathrm{~N}$ & $\mathrm{~N}$ & & $E$ & $E$ & & $E$ & & $\mathrm{M}$ & & & $E$ & $E$ & & $\mathrm{~N}$ \\
\hline 12 & & & & & & $M$ & $\mathrm{~N}$ & $E$ & $M$ & & $x$ & $x$ & $x$ & & $E$ & $\mathrm{M}$ & & $\mathrm{N}$ & $E$ & $E$ & & $E$ & E & & & $\mathrm{M}$ & M & $\mathrm{N}$ \\
\hline 13 & & & M & M & $M$ & $\mathrm{~N}$ & $E$ & $E$ & $M$ & $\mathrm{~N}$ & & & & $X$ & $x$ & $x$ & $X$ & $E$ & $E$ & $E$ & $E$ & $\mathrm{~N}$ & $M$ & $x$ & $\mathrm{E}$ & $M$ & $E$ & $E$ \\
\hline 14 & $\mathrm{~N}$ & $\mathrm{E}$ & & & $\mathrm{N}$ & $\mathrm{E}$ & $\mathrm{E}$ & $\mathrm{M}$ & M & $\mathrm{E}$ & & & & $X$ & $x$ & $X$ & $E$ & & $X$ & $\mathrm{~N}$ & $E$ & & $\mathrm{M}$ & M & $E$ & $E$ & & \\
\hline 15 & $\mathrm{E}$ & $\mathrm{N}$ & $\mathrm{E}$ & $x$ & $E$ & M & & $E$ & M & M & $\mathrm{N}$ & M & $\mathrm{N}$ & $X$ & $x$ & $X$ & M & $E$ & M & $\mathrm{N}$ & M & $\mathrm{M}$ & $x$ & $E$ & $x$ & $\mathrm{~N}$ & $\mathrm{~N}$ & $x$ \\
\hline 16 & M & $E$ & M & M & $E$ & $E$ & $\mathrm{~N}$ & $\mathrm{~N}$ & $M$ & & $E$ & M & $E$ & & & & $x$ & $X$ & $X$ & $E$ & $\mathrm{~N}$ & $\mathrm{~N}$ & $\mathrm{M}$ & $\mathrm{M}$ & $\mathrm{N}$ & $\mathrm{N}$ & $\mathrm{E}$ & $E$ \\
\hline 17 & & $M$ & $E$ & M & $E$ & $E$ & $M$ & & $\mathrm{~N}$ & $E$ & $M$ & $M$ & $M$ & & & & $x$ & $x$ & $x$ & $M$ & $E$ & $\mathrm{~N}$ & $\mathrm{~N}$ & $\mathrm{~N}$ & $\mathrm{~N}$ & $M$ & $\mathrm{~N}$ & $E$ \\
\hline 18 & $\mathrm{~N}$ & $E$ & $\mathrm{~N}$ & $\mathrm{~N}$ & & $\mathrm{~N}$ & $\mathrm{~N}$ & & $\mathrm{~N}$ & M & $M$ & $E$ & $E$ & $M$ & $E$ & $\mathrm{~N}$ & $X$ & $X$ & $x$ & $M$ & $\mathrm{~N}$ & $\mathrm{~N}$ & $E$ & $M$ & $E$ & $M$ & $E$ & M \\
\hline 19 & M & M & $\mathrm{N}$ & $E$ & $\mathrm{~N}$ & $E$ & $E$ & $M$ & $E$ & & $E$ & $\mathrm{~N}$ & $E$ & $\mathrm{M}$ & $E$ & $\mathrm{~N}$ & & & & $x$ & $X$ & $X$ & $\mathrm{~N}$ & $\mathrm{~N}$ & $\mathrm{~N}$ & $\mathrm{~N}$ & $\mathrm{~N}$ & $\mathrm{~N}$ \\
\hline 20 & $\mathrm{~N}$ & $\mathrm{M}$ & & $\mathrm{N}$ & M & & & $E$ & $\mathrm{~N}$ & $M$ & $\mathrm{~N}$ & $\mathrm{~N}$ & $\mathrm{E}$ & $\mathrm{N}$ & $\mathrm{N}$ & $\mathrm{E}$ & & & & $x$ & $X$ & $x$ & $\mathrm{E}$ & $\mathrm{M}$ & $\mathrm{N}$ & $\mathrm{E}$ & M & $\mathrm{M}$ \\
\hline 21 & $E$ & $\mathrm{~N}$ & M & $M$ & $E$ & & & $\mathrm{~N}$ & & $M$ & $\mathrm{~N}$ & $\mathrm{M}$ & $M$ & $M$ & $E$ & $E$ & $E$ & $\mathrm{M}$ & $\mathrm{M}$ & $X$ & $x$ & $x$ & $M$ & $\mathrm{~N}$ & $E$ & $\mathrm{~N}$ & $E$ & $\mathrm{~N}$ \\
\hline 22 & $E$ & $M$ & $\mathrm{~N}$ & $M$ & $E$ & & $\mathrm{~N}$ & $E$ & $E$ & $\mathrm{~N}$ & $E$ & $E$ & $M$ & $M$ & M & $E$ & $M$ & $E$ & $E$ & & & & $x$ & $x$ & $x$ & $M$ & $E$ & $M$ \\
\hline 23 & M & $\mathrm{N}$ & $\mathrm{E}$ & & M & $E$ & $\mathrm{~N}$ & M & & & M & $\mathrm{N}$ & $E$ & M & M & $\mathrm{M}$ & M & $E$ & $\mathrm{~N}$ & & & & $X$ & $\mathrm{X}$ & $X$ & $\mathrm{M}$ & $\mathrm{E}$ & $\mathrm{N}$ \\
\hline 24 & $\mathrm{~N}$ & $E$ & M & $E$ & $E$ & $\mathrm{~N}$ & $E$ & $\mathrm{~N}$ & $E$ & $\mathrm{E}$ & $\mathrm{M}$ & $\mathrm{N}$ & $\mathrm{N}$ & $\mathrm{N}$ & $\mathrm{N}$ & $\mathrm{N}$ & $\mathrm{N}$ & $\mathrm{E}$ & $\mathrm{M}$ & $\mathrm{N}$ & $E$ & $\mathrm{M}$ & $\mathrm{X}$ & $x$ & $X$ & $\mathrm{~N}$ & $\mathrm{M}$ & M \\
\hline 25 & $E$ & $M$ & $E$ & $\mathrm{~N}$ & $\mathrm{~N}$ & $M$ & $\mathrm{~N}$ & $\mathrm{~N}$ & $M$ & $\mathrm{E}$ & $E$ & $\mathrm{M}$ & $\mathrm{N}$ & $E$ & M & $E$ & $M$ & $M$ & $\mathrm{~N}$ & $\mathrm{~N}$ & $E$ & $\mathrm{~N}$ & & & & $X$ & $X$ & $x$ \\
\hline 26 & M & $\mathrm{E}$ & M & $M$ & & $\mathrm{E}$ & $\mathrm{M}$ & $\mathrm{N}$ & & $\mathrm{N}$ & $\mathrm{M}$ & $\mathrm{E}$ & $\mathrm{N}$ & $\mathrm{N}$ & $\mathrm{N}$ & $\mathrm{M}$ & $\mathrm{M}$ & $\mathrm{M}$ & $E$ & $\mathrm{~N}$ & $\mathrm{~N}$ & $\mathrm{~N}$ & & & & $X$ & $X$ & $X$ \\
\hline 27 & $\mathrm{~N}$ & $E$ & M & $E$ & $\mathrm{~N}$ & $\mathrm{~N}$ & $E$ & $E$ & $\mathrm{~N}$ & $E$ & $E$ & $\mathrm{~N}$ & $E$ & $\mathrm{~N}$ & $E$ & $M$ & $\mathrm{~N}$ & $E$ & $\mathrm{~N}$ & $M$ & $\mathrm{M}$ & $\mathrm{E}$ & $\mathrm{N}$ & $\mathrm{M}$ & M & $X$ & $x$ & $x$ \\
\hline 28 & $\mathrm{~N}$ & $x$ & $E$ & $M$ & $\mathrm{~N}$ & $E$ & $\mathrm{~N}$ & $\mathrm{E}$ & & $M$ & $x$ & $\mathrm{~N}$ & $X$ & $\mathrm{~N}$ & $M$ & $M$ & $M$ & $\mathrm{~N}$ & $M$ & $M$ & $E$ & $\mathrm{~N}$ & $\mathrm{E}$ & $E$ & $\mathrm{~N}$ & & & \\
\hline
\end{tabular}

( $\mathrm{M}=$ Morning, $\mathrm{E}=$ Evening, $\mathrm{N}=$ Night, $\mathrm{X}=$ Midnight $)$

Table 2 shows the working-day and off-day shift arrangements for 28 police officers for the 28-day (4week) scheduling period developed using the goal programming model. In the goal programming 
schedule, this schedule can only be observed to satisfy a few of the hard constraints and soft constraints. Goal 1 is achieved here, on the basis of the above-mentioned schedule. But, Goal 2 is not fulfilled where $14.29 \%$ of police officers have to work on the night shift followed by the midnight shift on the next day, and Goal 3 is also not fulfilled where $60.71 \%$ of police officers have to work on the night shift followed by the morning shift on the next day is assigned to each schedule's pattern.

Table 3: Summary of the number of shifts of each police officer

\begin{tabular}{lllllllllllllllllllllllllllll}
\hline $\begin{array}{l}\text { Police } \\
\text { Officer }\end{array}$ & $\mathbf{1}$ & $\mathbf{2}$ & $\mathbf{3}$ & $\mathbf{4}$ & $\mathbf{5}$ & $\mathbf{6}$ & $\mathbf{7}$ & $\mathbf{8}$ & $\mathbf{9}$ & $\mathbf{1 0}$ & $\mathbf{1 1}$ & $\mathbf{1 2}$ & $\mathbf{1 3}$ & $\mathbf{1 4}$ & $\mathbf{1 5}$ & $\mathbf{1 6}$ & $\mathbf{1 7}$ & $\mathbf{1 8}$ & $\mathbf{1 9}$ & $\mathbf{2 0}$ & $\mathbf{2 1}$ & $\mathbf{2 2}$ & $\mathbf{2 3}$ & $\mathbf{2 4}$ & $\mathbf{2 5}$ & $\mathbf{2 6}$ & $\mathbf{2 7}$ & $\mathbf{2 8}$ \\
\hline Morning & 5 & 6 & 7 & 8 & 5 & 5 & 5 & 4 & 8 & 6 & 8 & 6 & 4 & 6 & 5 & 6 & 6 & 4 & 6 & 4 & 4 & 4 & 8 & 9 & 4 & 7 & 6 & 6 \\
Evening & 5 & 8 & 8 & 6 & 8 & 8 & 6 & 8 & 4 & 7 & 5 & 4 & 8 & 5 & 6 & 7 & 6 & 10 & 4 & 6 & 8 & 7 & 6 & 4 & 6 & 6 & 8 & 4 \\
Night & 8 & 3 & 3 & 3 & 5 & 5 & 7 & 6 & 6 & 5 & 3 & 7 & 4 & 7 & 7 & 4 & 5 & 4 & 6 & 7 & 5 & 7 & 3 & 4 & 6 & 5 & 4 & 6 \\
Midnight & 3 & 4 & 3 & 4 & 3 & 3 & 3 & 3 & 3 & 3 & 5 & 4 & 5 & 3 & 3 & 4 & 4 & 3 & 5 & 4 & 4 & 3 & 4 & 4 & 5 & 3 & 3 & 5 \\
\hline Total & 21 & 21 & 21 & 21 & 21 & 21 & 21 & 21 & 21 & 21 & 21 & 21 & 21 & 21 & 21 & 21 & 21 & 21 & 21 & 21 & 21 & 21 & 21 & 21 & 21 & 21 & 21 & 21 \\
\hline Day-off & 7 & 7 & 7 & 7 & 7 & 7 & 7 & 7 & 7 & 7 & 7 & 7 & 7 & 7 & 7 & 7 & 7 & 7 & 7 & 7 & 7 & 7 & 7 & 7 & 7 & 7 & 7 & 7 \\
\hline
\end{tabular}

Table 3 presents a summary of the number of shifts for each police officer and the total number of working days and days-off for the pattern of thisschedule. The day-off for every police officer is equal to 7 days. Goal 1 is achieved where all police officers in the schedule pattern have the same number of working days that are 21 days in the 28-day planning period.

Table 4: Summary of the number of police officer in each shift

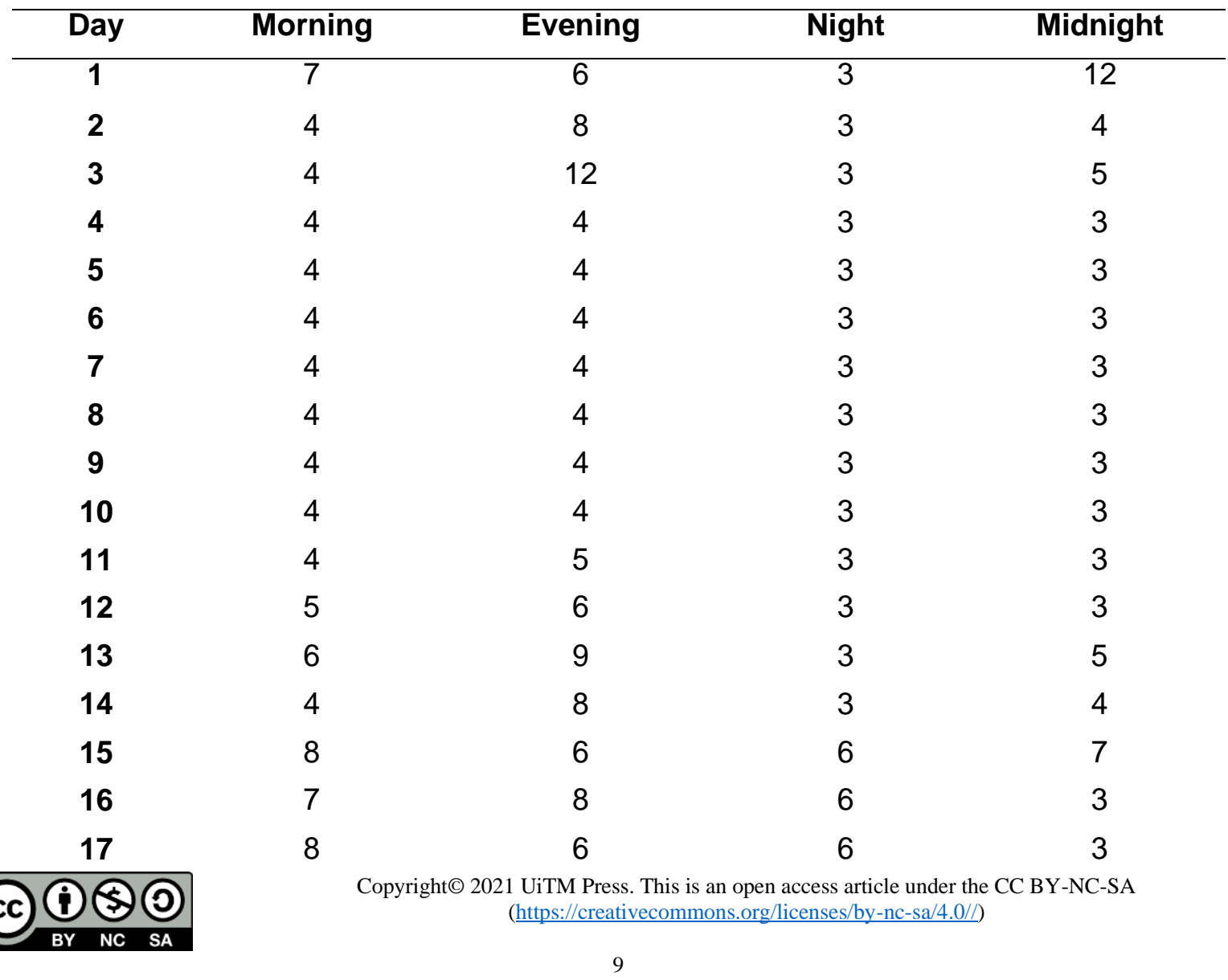




$\begin{array}{llccc}\mathbf{1 8} & 7 & 7 & 9 & 3 \\ \mathbf{1 9} & 4 & 7 & 10 & 3 \\ \mathbf{2 0} & 6 & 5 & 8 & 3 \\ \mathbf{2 1} & 9 & 7 & 6 & 3 \\ \mathbf{2 2} & 8 & 10 & 3 & 3 \\ \mathbf{2 3} & 9 & 5 & 5 & 3 \\ \mathbf{2 4} & 6 & 8 & 11 & 3 \\ \mathbf{2 5} & 7 & 7 & 8 & 3 \\ \mathbf{2 6} & 8 & 4 & 8 & 3 \\ \mathbf{2 7} & 6 & 10 & 9 & 3 \\ \mathbf{2 8} & 7 & 6 & 8 & 3\end{array}$

Table 4 shows the summary of the number of police officers for each shift according to the schedule that developed by the goal programming method. The distribution of police officers for each shift also satisfies the minimum number of police officers required for each shift during the 28-day planning period. The table above shows that the number of police officers required for each shift is achieved.

There are a few points that can be emphasized as a result of the new schedule produced using the goal programming method. First, for three consecutive midnight shifts, every police officer has two day-offs. Then the day-off for every police officer is 7 days in 28 days. The result shows that the number of police officers needed for each shift is fulfilled.

The 0-1 goal programming schedule, which is pre-emptive method, produced a balanced shift distribution compared to the manual schedule made by the scheduler. The above result shows the same total number of working days for each police officer in a 4-week schedule of 21 days. All police officers also have the same number of days-off based on the new schedule generated.Thus, this scheduling result gives police officers more satisfaction than the manual scheduling since the total number of working days is the same. There is no need for police officers to feel being treated unequally when all police officers have the same pattern of scheduling and number of shifts.

But, not all goals in this study are satisfied which only Goal 1 is satisfied. Goal 2 and Goal 3 are not satisfied as there are $14.29 \%$ of police officers who have to work on night shift followed by midnight shift on the next day and $60.71 \%$ of police officers have to work on night shift followed by morning shift on the next day.

\section{CONCLUSION AND RECOMMENDATIONS}

The schedules of police officers must be well prepared and organized to ensure job satisfaction among all police officers. The criminal unit of 24-hour department in IPD Kuala Muda uses a 4-week schedule to assign four shifts to its police officers. The new optimal schedule that has been generated using goal programming in this study give more satisfaction to police officers as all of them have the same number of working days and number of days-off. It also makes work easier for the scheduler to assign a shift to each police officer using the software, as it can be generated in a short time. This means that the new optimal schedule is achieved and is better than the previous manual schedule. Not only IPK Kuala Muda but many 
other sectors who are having shift works could apply Goal Programming (GP) to generate a better shift schedule within a very short period of time. However, sometimes not all the set up goals are achieved because of various constraints. For future research, it is recommended to extend the study by using other mathematical models such as hybrid swarm-based optimization and many other constraints which are suitable with the situation might be considered in the model.

\section{ACKNOWLEDGMENTS}

The authors express sincere gratitude and thanks especially to the officers of IPD Kuala Muda for their contributions and supports in giving us information during interviews to complete our study and also people who helps us direct and indirectly in this study.

\section{REFERENCES}

Agyei, W., Obeng-Denteh, W., \& Andaam, E. A. (2015). Modeling nurse scheduling problem using 0-1 goal programming: A case study of Tafo Government Hospital, Kumasi-Ghana. International Journal of Scientific \& Technology Research, 5-10.

Colapinto, C., Jayaraman, R., \& La Torre, D. (2020). Goal programming models for managerial strategic decisionmaking. In Applied Mathematical Analysis: Theory, Methods, and Applications, 487-507.

Dan, E. D., \& .O., O. D. (2013). Goal programming: An application to budgetary allocation of an institution of higher learning. Research Journal in Engineering and Applied Sciences, 95-105.

Hassell, K. D., Archbold, C. A., \& Stichman, A. J. (2011). Comparing the Workplace Experiences of Male and Female Police Officers: Examining Workplace Problems, Stress, Job Satisfaction and Consideration of Career Change. International journal of police science \& management, 37-53.

Kumar, P. P. (2019). Goal Programming Through Bakery Production. International Journal Of Scientific \& Technology Research, 3722-3725.

Mahmud, N., Jamaluddin, S. H., Hamidun, I. S., \& Pazil, N. S. (2018). Optimization of Workforce Scheduling using Integer Goal Programming Approach. Jurnal Intelek, 27-36.

Mat Salleh, S.S., Jamian, N.H. \& Ali, N. (2019). Team Teaching Load Using Linear Programming. Journal of Computing Research and Innovation, 8-15

Musliu, N., Schutt, A., \& Stuckey, P. J. (2018). Solver independent rotating workforce scheduling. International Conference on the Integration of Constraint Programming, Artificial Intelligence, and Operations Research, 429-445.

Peterson, S. A., Wolkow, A. P., Lockley, S. W., O'Brien, C. S., Qadri, S., Sullivan, J. P., . . Barger, L. K. (2019). Associations between shift work characteristics, shift work schedules, sleep and burnout in North American police officers: a cross-sectional study. BMJ open, 9(11).

Punluekdej, T. (2020). Quality Of Work Life Of Police Officers: A Case Study Of A Police Station In Bangkok Metropolis. International Academic Multidisciplinary Research Conference In Switzerland 2020, 252-261.

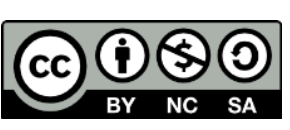

Copyright@ 2021 UiTM Press. This is an open access article under the CC BY-NC-SA (https://creativecommons.org/licenses/by-nc-sa/4.0//) 
Journal of Computing Research and Innovation (JCRINN) Vol. 6 No. 3 (2021) (pp1-12)

https://jcrinn.com : eISSN : 2600-8793

Todovic, D., Makajic-Nikolic, D., Kostic-Stankovic, M., \& Martic, M. (2015). Police officer scheduling using goal programming. Policing: An International Journal of Police Strategies \& Management., 295-312. 